\title{
Estrogen Receptor Genes Polymorphisms and Susceptibility to Juvenile and Adult Onset Systemic Lupus Erythematous in Egyptian Patients
}

Rania Hassan Khalifa ${ }^{1 *}$, Abeer Nabil Mokbel ${ }^{2}$, Mohamed Abdallah Kamel', Engy Mohammed and Hend Hamed Tamim ${ }^{1}$

${ }^{1}$ Department of Clinical Pathology, Kasr Al-Aini hospital, Cairo University, Egypt

${ }^{2}$ Department of Rheumatology, Kasr Al-Aini hospital, Cairo University, Egypt

\begin{abstract}
Background: Estrogens, acting through their cellular receptors namely alpha and beta, have a role in the development of systemic lupus erythematosus (SLE).

Objectives: To investigate whether polymorphisms of ESR1 and ESR2 genes is related to the susceptibility of juvenile (jSLE) and adult Systemic lupus erythematosus (aSLE) and to detect their association with clinical and laboratory characteristics of the disease.

Methods: Genomic DNA was extracted from 32 adult onset SLE (aSLE), 33 juvenile onset SLE (jSLE) and 60 age and gender matched controls. Genotyping of ESR1 and ESR2 was done using the restriction fragment length polymorphism (RFLP) and tetra primer ARM-PCR methods respectively.

Results: There was a statistically significant difference in the genetic polymorphisms of ESR2 between the two studied groups (aSLE, jSLE) and the control group as regards the homomutant AA genotype (OR:0.058, $p$ value: 0.000 ) and the A allele(OR: 0.195, $p$ value:0.007) in case of aSLE, and in homomutant AA genotype (OR:0.269, $p$ value:0.017) and the A allele (OR: $0.397, p$ value: 0.003 ) in case of $j S L E$ but the study could not find any statistically significant difference in the genetic polymorphisms of ESR1 between the control and the two groups.

Conclusion: This study revealed that ESR1 genetic polymorphism is not genetic risk or protective factor for neither aSLE nor jSLE susceptibility, but ESR2 genetic polymorphism is reported as protective factor for aSLE and jSLE among our studied population. Certain alleles are associated with certain clinical and laboratory parameters.
\end{abstract}

Keywords: Systemic lupus erythematosus; Estrogen receptors; Restriction fragment length polymorphism; Tetra primer ARM-PCR

\section{Introduction}

Systemic lupus erythematosus (SLE) is a prototype for systemic human autoimmune disease affecting most major organ systems [1]. The reported prevalence of systemic lupus erythematosus (SLE) in the population is 20 to 150 cases per 100,000 [2]. Both geography and race affect the prevalence of SLE and of frequency and severity of clinical and laboratory manifestations [3].

Epidemiologically, a female predominance is consistently demonstrated (about $90 \%$ of adult SLE) [4], which can be explained by the presence of two X chromosomes which carry immunologically related genes which can mutate and contribute to the onset of SLE [5]. 10-15\% of SLE cases start in childhood with observed female predominance however not as high as in adults which is due to different hormonal milieu in children (low concentration of sex hormones and different oestrogen profile) [6].

SLE is genetically complex, with contributors anticipated from environmental, gene or gene-environmental factors in the pathogenesis [7].

SLE predominantly affects the females; this preponderance of female sex implies an important role of sex hormones such as estrogen in SLE pathogenesis. The peak incidence of SLE occurs in the reproductive period, and a postmenopausal onset of SLE is relatively uncommon [8].

Estrogens are the primary female sex hormones which have proinflammatory properties that might predispose to disease development [9]. Estrogen stimulates the production of autoantibody to dsDNA in peripheral blood mononuclear cells (PBMC), and decreases apoptosis of PBMC in SLE patients. In addition, estrogen augments SS-A/Ro and SSB/La antigen expression on the cell surface of human keratinocytes, and stimulates macrophages from SLE patient to produce IL-10, the levels of which increase in sera of SLE patients. Recently it was reported that estrogen increased calcineurin and CD40 ligand in SLE T cells. Some epidemiological studies have suggested that women taking postmenopausal hormone replacement or oral contraceptives could beat increased risk of developing SLE [10].

Estrogens act through estrogen receptors (ERs), which are a group of proteins found inside the cells. There are two different forms of the estrogen receptors, usually referred to as alpha and beta, each encoded by a separate gene (ESR1 and ESR2 on the sixth chromosome 6q25.1 (MIMI33430) and fourteenth chromosome 14q23.2(MIM601663) respectively [11].

A possible correlation of ESR gene polymorphisms and of quantitative and qualitative changes in disease aetiopathogenesis has been reported [12].

Hence the purpose of this study is to determine whether the polymorphisms of ESR1 and ESR2 genes confer susceptibility to adult and juvenile onset SLE and to investigate the association of

*Corresponding author: Rania Hassan Khalifa, Assisstant Professor, Department of Clinical Pathology, Cairo University, Egypt, Tel: 02-01001424415; E-mail: drrhk@hotmail.com

Received July 07, 2015; Accepted September 08, 2015; Published September 12, 2015 Citation: Khalifa RH, Mokbel AN, Kamel MA, El-Khateeb EM, Tamim HH (2015) Estrogen Receptor Genes Polymorphisms and Susceptibility to Juvenile and Adult Onset Systemic Lupus Erythematous in Egyptian Patients. J Mol Biomark Diagn 6: 245. doi:10.4172/2155-9929.1000245

Copyright: (c) 2015 Khalifa $\mathrm{RH}$, et al. This is an open-access article distributed under the terms of the Creative Commons Attribution License, which permits unrestricted use, distribution, and reproduction in any medium, provided the original author and source are credited 
Citation: Khalifa RH, Mokbel AN, Kamel MA, El-Khateeb EM, Tamim HH (2015) Estrogen Receptor Genes Polymorphisms and Susceptibility to Juvenile and Adult Onset Systemic Lupus Erythematous in Egyptian Patients. J Mol Biomark Diagn 6: 245. doi:10.4172/2155-9929.1000245

polymorphisms with different clinical and laboratory parameters of the disease.

\section{Subjects and Methods}

\section{Patients}

A total of 125 subjects, recruited over the period of one year, were enrolled in the study, they consisted of 3 groups; group 1 were adult onset SLE $(n=32)$, group 2 were juvenile onset SLE $(n=33)$, group 3 were healthy control subjects $(\mathrm{n}=60)$ matched for age and gender. Patients were attending the outpatient clinic or the inpatient wards of the Department of Rheumatology and Rehabilitation, Faculty of Medicine, Cairo University. All patients were fulfilling the American College of Rheumatology (ACR) revised criteria for diagnosis of SLE [13].

Detailed clinical records are available for all the patients and were used in this study.

Informed consent was obtained from all cases. The aims and the value of the work was discussed with them focusing on the importance of the work in the future of SLE in our community. Ethical approval was obtained from local Ethics committee.

\section{Methods}

Sampling: For each patient and control, 3-5 ml of venous blood was collected on ethylene diamine tetra-acetic acid (EDTA) by sterile venipuncture using a sterile vacutainer tube. Samples were either stored in the same vacutainer at $-2^{\circ} \mathrm{C}$ or used directly within 24 hours for genomic DNA extraction.

\section{Genotyping}

Genotyping of ESR1 (rs2234693) polymorphism: DNA was isolated from whole-blood samples using QIAamp DNA blood Mini kit-Qiagen (from Hoffmann-La Roche AG, Hilden, Germa).

The restriction fragment length polymorphism (RFLP) method was used. The primers were: forward primer 5' CAT GAA CCA CCA TGC TCA GT 3', reverse primer 5' ACC ACA CTC AGG GTC TCT GG 3'. PCR was performed in a total volume of $10 \mathrm{ul}$ containing $200 \mathrm{ng}$ of DNA, 25 pmol of each primer, $200 \mathrm{uM}$ of each dNTP, $1 \mathrm{ul}$ of magnesium chloride, $1 \mathrm{ul}$ of $10 \mathrm{x}$ reaction buffer and $0.8 \mathrm{U}$ of Taq DNA polymerase. The PCR conditions consisted of 32 cycles of $30 \mathrm{sec}$ at $95^{\circ} \mathrm{C}, 55 \mathrm{sec}$ at $63^{\circ} \mathrm{C}$ and $60 \mathrm{sec}$ at $72^{\circ} \mathrm{C}$. PCR product was then digested using $5 \mathrm{U}$ of PvuII restriction enzyme and electrophoresed in agarose gel. The wild

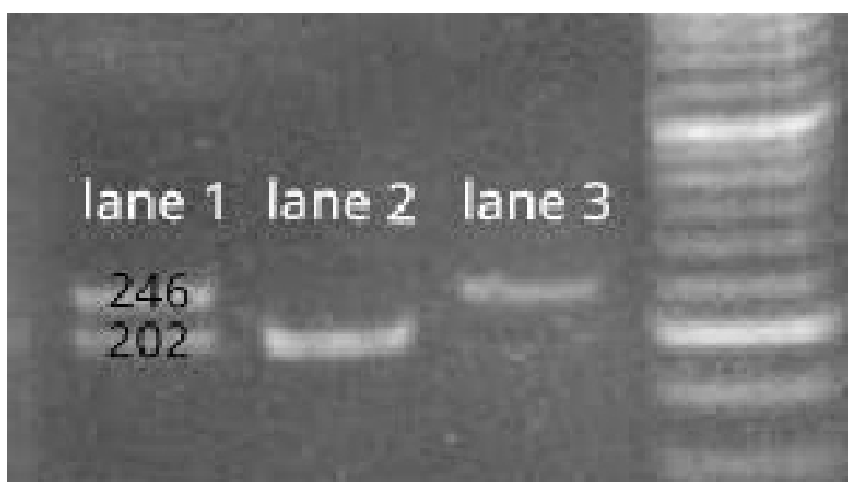

Figure 1: Electrophoresis image of the ESR1 genotyping visualized by ethidium bromide staining on agarose gel. The lengths of the DNA fragments are (1) $246 \mathrm{bp}$ and $202 \mathrm{bp}$ for the TC genotype, (2) $202 \mathrm{bp}$ for the TT genotype (3) 246 bp for the CC genotype.(44 bp couldn't be seen).

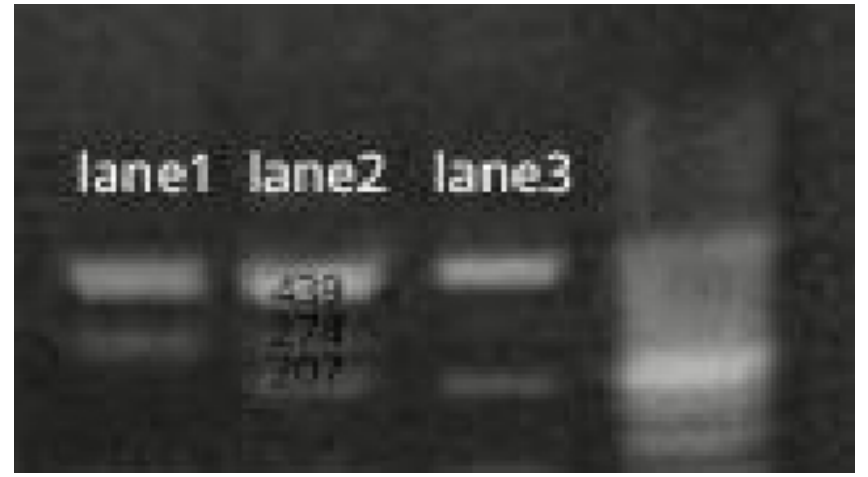

Figure 2: Electrophoresis image of tsahe ESR2 genotyping visualized by ethidium bromide staining on agarose gel. The lengths of the DNA fragments are (1) $439 \mathrm{bp}$ and $274 \mathrm{bp}$ for the GG genotype, (2) $439 \mathrm{bp}, 274 \mathrm{bp}$ and $207 \mathrm{bp}$ for the GA genotype (3) $439 \mathrm{bp}$ and $207 \mathrm{bp}$ for the AA genotype.

homozygous genotype (TT) appeared as a two bands of 202 bp and 44 $\mathrm{bp}$, While the homomutant genotype (CC) appeared as a single band of $246 \mathrm{bp}$, and the heteromutant genotype (TC) appeared as three bands at 246bp, 202bp and 44bp (Figure 1) [6].

Genotyping of ESR2 (rs4986938) polymorphism: DNA was isolated from whole-blood samples using QIAamp DNA blood Mini kit-Qiagen (from Hoffmann-La Roche AG, Hilden, Germany).

Genotyping was performed by a tetra primer ARMPCR method, allowing the detection of homo- and heterozygous genotypes in a single test. The primers will be (5'-3') Forward outer AATCTCAGCACCTTTTTGTCCCC, Forward inner ACTGGCCCACAGAGGTCAAAA, Reverse outer GAAACGCTGCATTCAAATGTGC, Reverse inner CACTGGAGTTCACGCTTCATCC, Polymerase chain reaction (PCR) was performed in a total volume of $10 \mathrm{ul}$ containing: $200 \mathrm{ng}$ of DNA, $25 \mathrm{pmol}$ of each outer primer and $25 \mathrm{pmol}$ of each inner primer, $200 \mathrm{um}$ of each dNTP, $1 \mathrm{ul}$ of $10 \mathrm{x}$ reaction buffer, $1 \mathrm{ul}$ of magnesium chloride and $0.8 \mathrm{U}$ of Taq DNA polymerase. The PCR conditions consisted of 10 cycles of $10 \mathrm{sec}$ at $95^{\circ} \mathrm{C}, 30 \mathrm{sec}$ at $68.5^{\circ} \mathrm{C}$ and $30 \mathrm{sec}$ at $72^{\circ} \mathrm{C}$ followed by $22 \mathrm{cycles}$ of $10 \mathrm{sec}$ at $95^{\circ} \mathrm{C}, 30 \mathrm{sec}$ at $58^{\circ} \mathrm{C}$ and $30 \mathrm{sec}$ at $72^{\circ} \mathrm{C}$. After PCR, three products were observed on agarose gel electrophoresis one at $439 \mathrm{bp}$ (a constant control band, the product of the two outer primers), a 274-bp band specific for the $G$ allele (product of the forward outer and the reverse inner primers) and a 207-bp band specific for the A allele (product of the forward inner and the reverse outer primers) (Figure 2) [14].

\section{Statistical analysis}

Data was analyzed using IBM SPSS advanced statistics version 20 (SPSS Inc., Chicago, IL). Numerical data of scores were expressed as mean and standard deviation or median and range as appropriate. Qualitative data were expressed as frequency and percentage. Chisquare test (Fisher's exact test) was used to examine the relation between qualitative variables. For quantitative data, comparison between two groups was done using Mann-Whitney test (non-parametric t-test). Comparison between 3 groups was done using analysis of variance (ANOVA test) then post-Hoc "Schefe test" was used for pair-wise comparison. Odds ratio (OR) with it $95 \%$ confidence interval (CI) were used for risk estimation. A p-value $<0.05$ was considered significant.

\section{Results}

The different clinical and laboratory data of the adult SLE and juvenile SLE patients are shown in Table 1. 
Citation: Khalifa RH, Mokbel AN, Kamel MA, El-Khateeb EM, Tamim HH (2015) Estrogen Receptor Genes Polymorphisms and Susceptibility to Juvenile and Adult Onset Systemic Lupus Erythematous in Egyptian Patients. J Mol Biomark Diagn 6: 245. doi:10.4172/2155-9929.1000245

Page 3 of 5

\begin{tabular}{|c|c|c|c|c|c|}
\hline & & $\begin{array}{c}\text { jSLE(n=33) } \\
n(\%)\end{array}$ & $\begin{array}{c}\operatorname{aSLE}(n=32) \\
n(\%)\end{array}$ & Total $(n=65)$ & $P$ value \\
\hline \multirow{2}{*}{$\operatorname{Sex} n(\%)$} & Female & $28(84.8)$ & $31(96.9)$ & $59(90.8)$ & \multirow{2}{*}{0.197} \\
\hline & Male & $5(15.2)$ & $1(3.1)$ & $6(9.2)$ & \\
\hline \multirow{2}{*}{$\begin{array}{l}\text { Mucocutaneous } n \\
(\%)\end{array}$} & $-v e$ & $6(18.2)$ & $5(15.6)$ & 11(16.9) & \multirow{2}{*}{0.783} \\
\hline & $+v e$ & $27(81.8)$ & $27(84.4)$ & $54(83.1)$ & \\
\hline \multirow{2}{*}{$\begin{array}{l}\text { Muscloskeletal } \\
n(\%)\end{array}$} & -ve & $10(30.3)$ & $4(12.5)$ & $14(21.5)$ & \multirow{2}{*}{0.081} \\
\hline & $+\mathrm{ve}$ & $23(69.7)$ & $28(87.5)$ & $51(78.5)$ & \\
\hline \multirow{2}{*}{ Serositis n(\%) } & $-v e$ & 21(63.6) & $21(65.6)$ & $42(64.6)$ & \multirow{2}{*}{0.867} \\
\hline & $+\mathrm{ve}$ & $12(36.4)$ & $11(34.4)$ & $23(35.4)$ & \\
\hline \multirow{2}{*}{ Cardiac n(\%) } & $-v e$ & $22(66.7)$ & $14(43.8)$ & $36(55.4)$ & \multirow{2}{*}{0.063} \\
\hline & +ve & $11(33.3)$ & $18(56.3)$ & $29(44.6)$ & \\
\hline \multirow{2}{*}{ Chest n(\%) } & -ve & $30(90.9)$ & $26(81.3)$ & $56(86.2)$ & \multirow{2}{*}{0.303} \\
\hline & + ve & $3(9.1)$ & $6(18.8)$ & $9(13.8)$ & \\
\hline \multirow{2}{*}{$\begin{array}{l}\text { Lupus } \\
\mathrm{n}(\%)\end{array}$} & $-v e$ & $12(36.4)$ & $11(34.4)$ & $23(35.4)$ & \multirow{2}{*}{0.867} \\
\hline & $+v e$ & $21(63.6)$ & $21(65.6)$ & $42(64.6)$ & \\
\hline \multirow{2}{*}{$\begin{array}{l}\text { Lupus } \\
n(\%)\end{array}$} & $-v e$ & $24(72.7)$ & $22(68.8)$ & $46(70.8)$ & \multirow{2}{*}{0.724} \\
\hline & $+v e$ & $9(27.3)$ & $10(31.3)$ & 19(29.2) & \\
\hline \multirow{2}{*}{ Hematological n(\%) } & -ve & $16(48.5)$ & $15(46.9)$ & $31(47.7)$ & \multirow{2}{*}{0.897} \\
\hline & $+v e$ & $17(51.5)$ & $17(53.1)$ & $34(52.3)$ & \\
\hline \multirow{2}{*}{ ANA n(\%) } & $-v e$ & $7(21.2)$ & $5(15.6)$ & $12(18.5)$ & \multirow{2}{*}{0.562} \\
\hline & $+v e$ & $26(78.8)$ & $27(84.4)$ & $53(81.5)$ & \\
\hline \multirow{2}{*}{ dsDNA n(\%) } & $-v e$ & $20(60.6)$ & $13(40.6)$ & $33(50.8)$ & \multirow{2}{*}{0.107} \\
\hline & $+v e$ & $13(39.4)$ & $19(59.4)$ & $32(49.2)$ & \\
\hline
\end{tabular}

* $P$ is only statistically significant if $\leq 0.05$.

Table 1: The clinical and laboratory characteristics among patients with juvenile and adult SLE.

\begin{tabular}{|c|c|c|c|c|c|c|}
\hline & Gene & aSLE(32) & control(60) & OR & $95 \% \mathrm{Cl}$ & P value \\
\hline \multirow{5}{*}{ ESR1 } & TT & $7(21.9)$ & $6(10.0)$ & 1(reference) & - & - \\
\hline & $\mathrm{TC}$ & $14(43.8)$ & $28(46.7)$ & 0.889 & $0.375-2.107$ & 0.829 \\
\hline & $\mathrm{CC}$ & $11(34.4)$ & $26(43.3)$ & 0.685 & $0.281-1.669$ & 0.504 \\
\hline & $\mathrm{T}$ & $28 / 64(43.8)$ & $40 / 120(33.3)$ & \multirow{2}{*}{0.643} & \multirow{2}{*}{$0.345-1.19$} & \multirow{2}{*}{0.163} \\
\hline & C & $36 / 64(56.3)$ & $80 / 120(66.7)$ & & & \\
\hline \multirow{5}{*}{ ESR2 } & GG & $17(53.1)$ & $14(23.3)$ & 1(reference) & - & - \\
\hline & GA & $13(40.6)$ & $14(23.3)$ & 2.248 & $0.891-5.669$ & 0.097 \\
\hline & AA & $2(6.3)$ & $32(53.3)$ & 0.058 & $0.013-0.266$ & $0.000^{*}$ \\
\hline & G & $47 / 64(73.4)$ & $42 / 120(35.0)$ & \multirow{2}{*}{0.195} & \multirow{2}{*}{$0.1-0.38$} & \multirow{2}{*}{$0.007^{*}$} \\
\hline & A & $17 / 64(26.6)$ & $78 / 120(65.0)$ & & & \\
\hline
\end{tabular}

${ }^{*} \mathrm{P}$ is only statistically significant if $\leq 0.05$

Table 2: Comparison between aSLE patients and controls as regards the frequencies of ESR1 and ESR2 genotypes and alleles.

Results of genotyping of ESR1 (rs2234693) gene polymorphisms and ESR2 (rs4986938) in aSLE patients and controls.

Genotyping of ESR1 gene polymorphism by PCR-RFLP technique revealed no statistical significant difference between the patients and the controls while statistical significant difference was found between the patients and the control regarding the ESR2 (AA genotype and G,A alleles) (Table 2).

Results of genotyping of ESR1 (rs2234693) gene polymorphisms and ESR 2 (rs4986938) in jSLE patients and controls.

Genotyping of ESR1 gene polymorphism technique revealed no statistical significant difference between the patients and the controls in the distribution of the different genotypes and alleles. Statistical significant difference was found between the patients and the control regarding the ESR2 genetic polymorphism as regards homomutant (AA) and the polymorphic allele (A) allele of ESR2 gene, which

is significantly lower in adult SLE patients compared to controls. Calculated Odds ratio revealed that ESR2 gene polymorphism is associated with decreased risk of adult SLE (Table 3).

Association of genotypes and alleles with different clinical and laboratory parameters.

Distribution of the ESR1 alleles among aSLE stratified according to clinical and laboratory variables.

Statistical comparison showed no significant difference as regard mucocutaneous $(\mathrm{P}=0.664)$, muscloskeletal $(\mathrm{P}=0.721)$, serositis $(\mathrm{P}=$ $0.054)$, cardiac $(\mathrm{P}=0.253)$, chest $(\mathrm{P}=0.872)$, lupus nephritis $(\mathrm{P}=0.466)$, lupus cerebritis $(\mathrm{P}=0.135)$, hematological $(\mathrm{p}=0.659)$, but show statistical significant difference as regard ANA $(\mathrm{P}=0.012)$ and dsDNA $(\mathrm{P}=0.018)$.

Distribution of the ESR2 alleles among aSLE stratified according to clinical and laboratory variables.

Statistical comparison showed no significant difference as regard mucocutaneous $(\mathrm{P}=0.295)$, muscloskeletal $(\mathrm{P}=0.915)$, serositis ( $\mathrm{P}=0.199)$, cardiac $(\mathrm{P}=0.373)$, lupus nephritis $(\mathrm{P}=0.090)$, lupus cerebritis $(\mathrm{P}=0.423)$, hematological $(\mathrm{P}=0.583)$, ANA $(\mathrm{P}=0.789)$ and dsDNA $(\mathrm{P}=0.602)$, but show statistically significant difference as regard chest $(\mathrm{P}=0.041)$.

Distribution of the ESR1 alleles among jSLE stratified according to clinical and laboratory variables.

Statistical comparison showed no significant difference as regard mucocutaneous $(\mathrm{P}=0.259)$, musculoskeletal $(\mathrm{P}=0.539)$, serositis $(\mathrm{P}=$ $0.446)$, cardiac $(\mathrm{P}=0.722)$, chest $(\mathrm{P}=0.390)$, lupus nephritis $(\mathrm{P}=0.812)$, lupus cerebritis $(\mathrm{P}=0.237)$, ANA $(\mathrm{P}=0.350)$, dsDNA $(\mathrm{P}=0.522)$ but show statistical significant difference as regard hematological $(\mathrm{P}=0.020)$.

Distribution of the ESR2 alleles among jSLE stratified according to clinical and laboratory variables.

Statistical comparison showed no significant difference as regard mucocutaneous $(\mathrm{P}=0.953)$, musculoskeletal $(\mathrm{P}=0.793)$, serositis ( $\mathrm{P}=0.541)$, cardiac $(\mathrm{P}=0.379)$, chest $(\mathrm{P}=0.693)$, lupus nephritis ( $\mathrm{P}=0.672)$, lupus cerebritis $(\mathrm{P}=0.839)$, hematological $(\mathrm{P}=0.199)$, ANA $(\mathrm{P}=0.209)$ and dsDNA $(\mathrm{P}=0.988)$.

Combined haplotypes analysis of ESR1 and ESR2 in aSLE and the controls.

Combined haplotypes analysis revealed that the frequency of $\mathrm{CC} /$ GA combined genotype was higher in adult SLE patients compared to controls and conferred three folds increase risk of SLE ( $\mathrm{p}=0.046)$. However, the TC/AA combined genotype was significantly higher in

\begin{tabular}{|c|c|c|c|c|c|c|}
\hline & Gene & jSLE(33) & control(60) & OR & $95 \% \mathrm{Cl}$ & P value \\
\hline \multirow{5}{*}{ ESR1 } & TT & $4(12.1)$ & $6(10.0)$ & 1(reference) & & \\
\hline & TC & $17(51.5)$ & $28(46.7)$ & 0.911 & $0.224-3.698$ & 0.896 \\
\hline & CC & $12(36.4)$ & $26(43.3)$ & 0.692 & $0.164-2.917$ & 0.616 \\
\hline & $T$ & $26 / 66(39.4)$ & 40/120(33.3) & \multirow{2}{*}{0.82} & \multirow{2}{*}{$0.43-1.53$} & \multirow{2}{*}{0.534} \\
\hline & C & $40 / 66(60.6)$ & $80 / 120(66.7)$ & & & \\
\hline \multirow{5}{*}{ ESR2 } & GG & $13(39.4)$ & $14(23.3)$ & 1(reference) & & \\
\hline & GA & $12(36.4)$ & $14(23.3)$ & 0.923 & $0.314-2.716$ & 0.884 \\
\hline & AA & $8(24.2)$ & $32(53.3)$ & 0.269 & $0.091-0.794$ & $0.017^{*}$ \\
\hline & G & $38 / 66(57.6)$ & $42 / 120(35.0)$ & \multirow{2}{*}{0.397} & \multirow{2}{*}{$0.214-0.734$} & \multirow{2}{*}{$0.003^{*}$} \\
\hline & $A$ & $28 / 66(42.4)$ & $78 / 120(65.0)$ & & & \\
\hline
\end{tabular}

${ }^{*} P$ is only statistically significant if $\leq 0.05$.

Table 3: Comparison between jSLE patients and controls as regards the frequencies of ESR1 and ESR2 genotypes and alleles. 


\begin{tabular}{|c|c|c|c|c|c|}
\hline & aSLE $(n=32)$ & Control $(n=60)$ & OR & $95 \% \mathrm{Cl}$ & P-value \\
\hline TT/GG & 4 & 0 & 1 (Reference) & & \\
\hline TT/GA & 2 & 2 & 1.93 & $0.25-14.41$ & 0.608 \\
\hline TT/AA & 1 & 4 & 0.43 & $0.04-4.08$ & 0.65 \\
\hline TC/GG & 9 & 8 & 2.54 & $0.87-7.42$ & 0.09 \\
\hline TC/GA & 4 & 8 & 0.92 & $0.25-3.35$ & 0.91 \\
\hline TC/AA & 1 & 12 & 0.129 & $0.016-0.99$ & $0.031^{*}$ \\
\hline CC/GG & 4 & 6 & 1.24 & $0.23-4.75$ & 0.92 \\
\hline $\mathrm{CC} / \mathrm{GA}$ & 7 & 4 & 3.79 & $1.01-14.02$ & $0.046^{*}$ \\
\hline \multirow[t]{2}{*}{ CC/AA } & 0 & 16 & ND & & \\
\hline & jSLE(33) & Controls $(n=60)$ & OR & $95 \% \mathrm{Cl}$ & P-value \\
\hline TT/GG & 0 & 0 & 1 (Reference) & & \\
\hline TT/GA & 1 & 2 & 0.906 & $0.07-10.38$ & 0.937 \\
\hline TT/AA & 3 & 4 & 1.44 & $0.3-6.91$ & 0.641 \\
\hline TC/GG & 7 & 8 & 1.75 & $0.57-5.35$ & 0.382 \\
\hline $\mathrm{TC} / \mathrm{GA}$ & 9 & 8 & 2.43 & $0.88-7.09$ & 0.159 \\
\hline TC/AA & 1 & 12 & 0.125 & $0.015-1.009$ & $0.028^{*}$ \\
\hline CC/GG & 6 & 6 & 2 & $0.58-6.79$ & 0.335 \\
\hline $\mathrm{CC} / \mathrm{GA}$ & 2 & 4 & 0.9 & $0.156-5.21$ & 0.909 \\
\hline CC/AA & 4 & 16 & 0.37 & $0.11-1.24$ & 0.121 \\
\hline
\end{tabular}

${ }^{*} \mathrm{P}$ is only statistically significant if $\leq 0.05$.

Table 4: Comparison between aSLE and control, and the jSLE and the controls as regards Combined haplotypes analysis of ESR1 and ESR2.

control $(\mathrm{p}=0.031)$. Relative risk estimation revealed that this combined genotype is associated with decreased risk of adult SLE (Table 4).

Combined haplotypes analysis of ESR1 and ESR2 in jSLE and controls.

Combined haplotypes analysis revealed that the frequency of the TC/AA combined genotype was significantly higher in the control group $(\mathrm{p}=0.028)$. Relative risk estimation revealed that this combined genotype is associated with decreased risk of juvenile SLE (Table 4).

\section{Discussion}

PvuII polymorphisms of ESR1 have been studied in many diseases, and there are reports that these polymorphisms are associated with breast cancer [15], endometrial cancer [16], generalized osteoarthritis [17], osteoporosis [18], and the effects of estrogen replacement on lipid metabolism [19]. Also there are few reports in its association with SLE and with clinical and laboratory manifestations of the disease [6].

As regards ESR1 (rs2234693) gene polymorphism in SLE, our study has demonstrated that comparison between the controls and aSLE revealed no significant difference regarding genotypes and alleles. This goes in accordance with Kisiel et al. [6] and, Lee et al. [4], who found no significant difference between the two groups.

Also comparison done between the controls and jSLE revealed no significant difference regarding genotypes and alleles. On the contrary Kisiel et al. [6] found significant increase of the frequency of the $\mathrm{C}$ allele $(\mathrm{OR}=1.87, \mathrm{P}=0.006)$ and $\mathrm{CC}$ genotype $(\mathrm{OR}=1.56, \mathrm{P}=0.006)$ in jSLE group compared to the control, Calculated Odds ratio revealed that ESR1 gene polymorphism is associated with increased risk of jSLE. In contrary, Lee et al. [4] found significant difference between jSLE and controls as regard $\mathrm{CC}(\mathrm{OR}=0,95 \% \mathrm{CI}=0-0.63, \mathrm{P}=0.0045)$ which is higher in control, Calculated Odds ratio revealed that the presence of CC polymorphism is associated with decreased risk of jSLE.

Kisiel et al. [6] studied the role of ESR2 genetic polymorphism in SLE. We tried to replicate this association in our study. No statistical significant difference between the controls and aSLE, as regard GA

genotype, but there was a significant difference as regards homomutant $\mathrm{AA}$ and the A allele which are significantly lower in aSLE patients compared to controls. Calculated Odds ratio revealed that ESR2 gene polymorphism is associated with decreased risk of aSLE. These findings were not matching with that found by Kisiel et al. [6], where comparison between the two groups showed significant difference as regard $\mathrm{AA}:(\mathrm{OR}=1.46, \mathrm{P}=0.008)$ and $\mathrm{A}:(\mathrm{OR}=1.46, \mathrm{P}=0.008)$ which are higher in adult SLE patients compared to controls. Calculated Odds ratio revealed that ESR2 gene polymorphism is associated with increased risk of aSLE, also a report implicated this allele as a risk factor for Grave's disease [14]

The same was found in case of ESR2 polymorphisms in jSLE. The comparison between the control group and jSLE also revealed no significant difference as regard GA, but we found significant difference as regards homomutant (AA) and the polymorphic (A) allele which are significantly lower in juvenile SLE patients compared to controls. Calculated Odds ratio revealed that ESR2 gene polymorphism is associated with decreased risk of jSLE. These results go in contrary with Kisiel et al. [6], where no significant difference between jSLE and control was found.

The relation between the clinical characteristics and laboratory data of aSLE group of patients and different the ESR1 genotypes shows no statistically significant difference, also in relation to ESR1 allele no statistically significant difference could be found except for the statistically significant difference found as regards ANA $(\mathrm{p}=0.012)$, dsDNA (0.018) with increased frequency in the group carrying $C$ allele.

In case of the clinical characteristics and laboratory data of jSLE group of patients in relation to ESR1 genotypes, no statistically significant difference could be found and in relation to ESR1 allele no statistically significant difference could be found except a statistically significant difference that could be found as regards hematological manifestations $(\mathrm{p}=0.020)$ with increased frequency in the group carrying $\mathrm{T}$ allele. This goes in accordance with Kisiel et al. [6], who found no statistically significant association between the different genotypes and the clinical and laboratory data of the jSLE group of patients but in contrary he found statistical significant difference as regard lupus nephritis (0.02) and lupus cerebritis $(\mathrm{p}=0.005)$.

The case was also close to the results of the clinical characteristics and laboratory data of aSLE group of patients in relation to ESR2 alleles where no statistically significant difference could be found, except for the statistically significant difference found as regard chest manifestations ( $\mathrm{p}=0.041$ ) with decreased frequency in the group carring $\mathrm{G}$ allele. This goes with that found by Kisiel et al. [6], who found no statistically significant association between the clinical and laboratory data of the SLE group of patients and those genetic polymorphisms.

Concerning with the clinical characteristics and laboratory data of jSLE group of patients and their relation with ESR2 genotypes also no statistically significant association between the clinical and laboratory data of the SLE group of patients and those genetic polymorphisms.

The above mentioned discrepancies could represent differences in the genetic background between populations studied. Nevertheless, ethnic variation and genetic mixture have been considered in any evaluation of the genetic background of multifactorial diseases.

In this study by comparing jSLE and aSLE, we found no significant difference in the distribution of ESR1 and ESR2 genotyping and alleles between both groups. This was against what found by Kisiel et al. [6], who found that the homomutant of ESR1 (CC) in jSLE (34.5\%) and 
Citation: Khalifa RH, Mokbel AN, Kamel MA, El-Khateeb EM, Tamim HH (2015) Estrogen Receptor Genes Polymorphisms and Susceptibility to Juvenile and Adult Onset Systemic Lupus Erythematous in Egyptian Patients. J Mol Biomark Diagn 6: 245. doi:10.4172/2155-9929.1000245

in aSLE (19.6\%) revealing that ESR1 gene polymorphism is associated with increased risk of jSLE, He also found that the homomutant of ESR2 (AA) in jSLE (8.3\%) and in aSLE (16.1\%) revealing that ESR2 gene polymorphism is associated with increased risk of aSLE. In contrary to our results and the results of Kisiel et al. [6], Lee et al. [4], found that CC of ESR1 in aSLE (15.6\%) and in jSLE(0\%) and stated that SLE patients with the CC genotype were older at disease onset. Similar to Lee et al. [4], Johansson et al. [20], stated that carriers of pvuII C allele showed a later onset of SLE $(\mathrm{P}=0.02)$.

Our study uniquely analyzed the combined haplotypes of ESR1 and ESR2 in aSLE and control groups to add to the value of the results and revealed that the frequency of CC/GA combined genotype was higher in aSLE patients compared to controls and conferred three folds increase risk of aSLE (0.046). However, the TC/AA combined genotype was significantly higher in control $(\mathrm{p}=0.031)$. Relative risk estimation revealed that this combined genotype is associated with decreased risk of aSLE.

This combined haplotypes analysis of ESR1 and ESR2 was also done in jSLE and control groups and revealed that the frequency of the TC/ AA combined genotype was significantly higher in the control group $(\mathrm{p}=0.028)$, also denoting the protective role of this combined haplotype.

In conclusion our results revealed that ESR1 genetic polymorphism is not a genetic risk or protective factor for neither aSLE nor jSLE susceptibility, but ESR2 genetic polymorphisms is reported as protective factor for aSLE and jSLE susceptibility among our studied population suggesting new clues for the susceptibility of the disease.

An association was found between the ESR1 alleles distribution and laboratory data (ANA and dsDNA) in aSLE, and hematological manifestation in jSLE, in case of ESR2 allele distribution we found statistically significant association between the ESR2 alleles distribution and chest manifestation in aSLE and there was no statistically significant difference between aSLE and jSLE as regards the genetic polymorphism of the two genes or clinical or laboratory findings.

Background factors (genetic and otherwise) differentiating populations can modify the expression of a gene and lead to different levels of association. Even though our reported associations are not robust, there is a short-term benefit from this genetic association study, when included in a meta-analysis, which is a better understanding of disease pathogenesis. This will hopefully lead in turn to novel and better treatments and/or more tailored drug therapy.

\section{Competing Interest}

The authors declare that they have no competing interests.

\section{Funding Acknowledgements}

This research received no specific grant from any funding agency.

\section{References}

1. Harley JB, Moser KL, Gaffney PM, Behrens TW (1998) The genetics of human systemic lupus erythematosus. Curr Opin Immunol 10: 690-696.
2. Pons-Estel GJ, Alarcón GS, Scofield L (2010) Understanding the epidemiology and progression of systemic lupus erythematosus. Semin Arthritis Rheum 39-257.

3. Danchenko N, Satia JA, Anthony MS (2006) Epidemiology of systemic lupus erythematosus: a comparison of worldwide disease burden. Lupus 15-308.

4. Lee YJ, Shin KS, Kang SW, Lee CK, Yoo B, Cha HS, et al. (2004) Association of the oestrogen receptor a gene polymorphisms with disease onset in systemic lupus erythematosus. Ann Rheum Dis. 63: 1244-1249.

5. Tsokos GC (2011) Systemic Lupus Erythematosus. N Engl J Med 365: 2110-2121.

6. Kisiel BM, Kosin'ska J, Wierzbowska M, Rutkowska-Sak L, Musiej-Nowakowska E, et al. (2011) Differential association of juvenile and adult systemic lupus erythematosus with genetic variants of oestrogen receptors alpha and beta. Lupus 20: 85-89.

7. Vyis TJ, Kotzin BL (1996) Genetic basis of systemic lupus erythematosus. Curr Opin Immunol. 8: 843.

8. Walker SE (2002) The importance of sex hormones in systemic lupus erythematosus, s lupus erythematosus. Lippincott, Philadelphia, USA, 307-318.

9. McMurray RW, May W (2003) Sex hormones and systemic lupus erythematosus review and metaanalysis. Arthritis Rheum 48: 2100-2110.

10. Rider V, Jones S, Evans M, Bassiri H, Afsar Z, Abdou NI (2001) Oestrogen increases CD40 ligand expression in T cells from women with systemic lupus erythematosus. J Rheumatol 28: 2644-2649

11. Li X, Huang J, Yi P, Bambara RA, Hilf R, Muyan M (2004) "Single-chain estrogen receptors (ERs) reveal that the ERalpha/beta heterodimer emulates functions of the ER alpha dimer in genomic estrogen signaling pathways". Mol. Cell Biol 24: 7681-7694.

12. Kassi E, Moutsatsou P (2010) Estrogen Receptor Signaling and Its Relationship to Cytokines in Systemic Lupus Erythematosus. Journal of Biomedicine and Biotechnology

13. Hochberg MC (1997) Updating the American College of Rheumatology revised criteria for the classification of systemic lupus erythematosus. Arthritis Rheum 40: 1725

14. Kisiel B, Bednarczuk T, Kostrzewa G, Kosińska J, Miśkiewicz P et al. (2008) Polymorphism of the oestrogen receptor beta gene (ESR2) is associated with susceptibility to Graves' disease. Clin Endocrinol (Oxf) 68: 429-434.

15. Ramalhinho AC, Marques J, Fonseca-Moutinho J, Breitenfeld L ( 2013) Genetic polymorphims of estrogen receptor alpha -397 Pvull $(T>C)$ and -351 Xbal $(A>G)$ in a portuguese population: prevalence and relation with breast cancer susceptibility. Mol Biol Rep.

16. Zhou X, Gu Y, Wang DN, Ni S, Yan J(2013) Eight functional polymorphisms in the estrogen receptor 1 gene and endometrial cancer risk: a meta-analysis. PLoS One 8: e60851.

17. Wise BL, Demissie S, Cupples LA, Felson DT, Yang M, et al. (2009) The relationship of estrogen receptor-alpha and -beta genes with osteoarthritis of the hand. J Rheumatol 36: 2772-2279

18. Wang KJ, Shi DQ, Sun LS, Jiang X, Lü YY, Dai J, et al. (2012) Association of estrogen receptor alpha gene polymorphisms with bone mineral density: a meta-analysis. Chin Med J (Engl) 125: 2589-2597.

19. Sai AJ, Gallagher JC, Fang X (2011) Effect of hormone therapy and calcitriol on serum lipid profile in postmenopausal older women in association with estrogen receptor- $\alpha$ genotypes. Menopause 18: 1101-12.

20. Johansson M, Arlestig L, Moller B, Smedby T, Rantapaa S (2005) Oestrogen receptor alpha gene polymorphisms in systemic lupus erythematosis. Ann Rheum Dis 64: 1611-17. 